\title{
Thoughts on the Teaching Mode Reform of Prepress Processing Principle and Technology
}

\author{
Bo GAO \\ Department of Printing Engineering, Beijing Institute of Graphic Communication, Beijing, China \\ gaobozx@163.com
}

Keywords: Teaching reform, Prepress processing principle and technology, Teaching method.

\begin{abstract}
The prepress processing principle and technology is the core course of printing engineering. In recent years, the objects of the prepress processing get more fields, and it turns from the traditional book binding to a broader field of packaging development, also the processing quality requirements gets higher, the involving knowledge is extended, too. All these technology has a new development for intension and extension of post-press processing. Prepress processing principle and technology course keeps features of strong practicability and engineering practical. It plays a very important role on how to adapt to the training of senior engineering and technical personnel of project application by designing teaching mode. This paper takes a discussion from the building and reforming of teaching content, the application and improvement of teaching method, and the practice teaching.
\end{abstract}

\section{Introduction}

The focus for the attention and research of the current education reform is to cultivate students' engineering ability, innovation spirit and innovation ability.To realize the strategic goal of changing from a large engineering education country to a strong one, there is a task presses to solution. It is to train a large number various types of engineering and technical personnel who holds high innovative ability and can adapt to the economic and social development. It is the focus for the attention and research of the current education reform about how to cultivate the students' engineering ability, innovation spirit and innovation ability through the school teaching.

The prepress processing principle and technology is an important specialized core curriculum in printing engineering. It is very different from other professional courses. At the same time, it is also an important quality education curriculum, and plays an important role in the process of cultivating senior engineering and technical personnel.

Under the new situation, the course content puts emphasis on the integrity of the subject matter, systematic and logic of the knowledge, at the same time, it cares more about the enhancement of students' ability and comprehensive quality, and emphasizes the cultivation of students' practical ability and thinking ability. The teaching methods change from the traditional teacher lectures, students passively accept to mainly through the guidance of teachers to help students to accept knowledge. To realize this transformation, it is very important to reasonable choose the teaching content which is closely integrated with the actual production by deepening the reform of teaching content, to explore reasonable teaching mode and experiment teaching mode, constantly to enrich the content of practice teaching.

\section{Construction and Reform of Teaching Contents}

In terms of post-press processing, new technology emerges in endlessly, broadening the application field. In the teaching process, we should keep the part related to join the printing professional post-press courses. to establish reasonable post-press processing course system which is adapt to the modern printing undergraduate education, make teaching content more conform to the requirements of the subject, reasonable the knowledge structure, pay attention to the cross and fusion between disciplines, optimized integration of teaching content, and complete the cohesion between the it and other courses [1].To perfect experimental teaching resources, develop the experiment project in view of the course content and the difficulties, try to build a demonstration experiment course construction type and innovative design, 
validation experiments, enrich the students' practice of the experimental teaching environment, and cultivate the students' practice ability and innovation ability. At the same time we should pay attention to integrated teacher's scientific research achievements into classroom teaching, in order to form a more scientific and reflecting the new development of the teaching content, and can do timely adjustment and supplement according to the development of technology.

We also can hire enterprise engineering and technical personnel into the classroom to introduce some new technology, progress, development trend, and enterprise demands for students' knowledge, etc. Students reflect that the harvest is larger by hiring experts to do seminars and it also stimulates the students' learning initiative. It plays a role to pay attention to the importance of experiment and case teaching, enrich the students with the post-press processing knowledge, and to assign a small paper to make students to understand further with the problems of interest.

\section{Application and Improvement of Teaching Methods}

A perfect, scientific and effective teaching method is an important way to improve the students' learning enthusiasm, strengthening students' learning effect. The prepress processing principle and technology is a course holding both of theoretical and practical, functional and operational coexistence. While choosing the teaching methods, we must consider these factors. It not only can deepen the theoretical teaching, but also can develop students' understanding ability [2]. In addition to the use of heuristic teaching, research, we also can apply project teaching, case teaching and teaching methods, to maximize the realization of curriculum setting principle and process of finishing the basic teaching goal.

\section{Project Teaching Method}

Project teaching method is a piece of method that can strengthen the student's practical ability and innovation ability. We can converse the traditional system of academic knowledge content into a plurality of teaching project, organize teaching activities surrounding the project, make students to directly involved into the project of the whole process [3].Project teaching is a series of teaching action that the teachers and students carried out to accomplish specific tasks, emphasizing the completion of the project as the key point, trying to achieve a breakthrough in the whole system, and reflecting the ideas of innovation education in the teaching process. The main characteristic of project teaching lies in avoiding the traditional system, breaking the integrity and the systematic, the requirement of knowledge structure in line with the principle of "good enough", focusing on cultivating the students' ability of hands-on practice, independent in accessing to information and the ability of independent construction of knowledge, and the cultivation of innovative ability.

\section{Case Teaching}

Case teaching is an effective way to improve students' abilities. The purpose of implementation of case teaching is to make the students become the main body of teaching, to ask the students to the actual management or parties point to discover, analysis, disposal, or solve specific problems. The specific functions of the case teaching: case teaching is the best method of transforming knowledge into skills. It can effectively shorten the distance between students in the classroom with the community, and make students to be practiced through the case teaching. Case teaching can deepen the acquirement of students' knowledge. Appropriate cases can make students feel as if place themselves among it. Obtaining realistic fun at the same time, they can explore essence through the phenomena, and enhance their ability and consciousness to find, analyses, and solve problems. Case teaching can be a tool of connecting theory with practice. Using the case to guide students to discuss enable students to acquire perceptual knowledge, and then combine the case with theory, take a drill and gain the special practice experience with the theory guiding.

In the teaching of prepress processing principle and technology, the application of case teaching must be closely combined with the actual technology, use the typical application, system, perfect teaching cases, to show the actual operation technology of each link, make the case keeps the characteristics of objective and accurate, to guide students to understand, analyze, to explore the methods to solve the problems, and to improve the students' ability to discover, analyze and solve problems. 


\section{Make Full Use of Simulation Training}

Simulation training mainly refers to in the classroom teaching process the professional teachers make use of the teaching cases, exercises and multimedia teaching to improve the students' skills of mastering knowledge. It is an extension and amplification of case teaching content, through the repeated simulation training, to strengthen the students' professional knowledge theory and practical skills.

For such a course of strong practical as prepress processing principle and technology, it is easy to feel dull and cause bad teaching effect if only teachers in the classroom introduce all kinds of processing methods and make students as audience. Students' knowledge features of mechanical system and electric control system are relatively weak, which makes it difficult to understand the curriculum. Therefore, teachers should study the teaching law, method and means to arouse the students' interest and enthusiasm and to improve their understanding ability. As in the teaching of "folding" technology, there are many different ways in folding form. It cannot only using a general teaching or pictures. Because of the lack of understanding with it for the students it is easy to cause ignorant understanding and bad effect. The using dynamic display can be a good solution to the problem.

\section{Strengthening the Link of Practice Teaching}

The ways to cultivate the students' ability of engineering practice are varied. We focus on the use of laboratory teaching, the conventional simulation training, social practice, teaching and development of virtual experiment and other methods to improve and develop students' understanding and practice ability.

\section{Laboratory Teaching}

Laboratory teaching refers to a teaching method that through laboratory experiment teaching, in the form of teaching, aims to enable students to learn professional knowledge with the concrete practice [4]. The basic function of experimental teaching is to train the students' practical ability, and it is an effective way to realize the integration of theory with practice.

Because of a very strong practical requirement for printing technology, most of the professional courses are made of trainings, so that the experiment teaching could be a powerful complement to classroom teaching.

It organizes discussion on experimental teaching method and mode, through deepening teaching content construction, to make reasonable choice of the curriculum content which is closely integrated with the actual production. It also puts the operating procedures reasonable decomposition, in order to get better utilize existing experiment equipment for teaching.

\section{Field Teaching}

Field teaching could strengthen the ability of students' theory and practice. With the proper choice of some chapters, in the laboratory or production site binding equipment specific to explain, the teacher let the students to learn from practice, the actual application of the equipment, so that the students often have great enthusiasm in learning. In addition, the field teaching provides a large number of photos, pictures, videos, to make the students to have a more intuitive understanding, so as to make up for the "knowledge node" that factory site practice may encounter which is difficult to fully display. For example, in the folding machine type and process, it can be combined with folding machine experiment, through site on folding process knowledge, through a small fence folding mobile hand operation experiment, and then makes the students understand the processes of hybrid folding machine. In this field experiment teaching process, it emphasizes on the initiative of students, and to improve students' thinking, hands-on, practical skills.

\section{Develop Part of the Virtual Experiment}

Different from the basic experiment, post-press processing uses larger experimental equipment, and takes stronger risk. Most experimental equipment is in the form of single sets. For hundreds of people take part in the experiment course, an experiment often takes a long time to complete. Therefore, except for some 
simple principles, using demonstration method, which is operated by the experimenter and recorded by the students. The principle is relatively complex, and it takes the verification method, to be explained and operated by the clerk, then completed by students with setting some results. But for some complex large-scale laboratory equipment, the use of computer technology, VB programming language and development of the virtual simulation experiment of digital, not only can overcome the experimental equipment and space, but also can provide a broader learning platform for students. Students can use these virtual experiment to continuous learn and inquiry. It enhances the students the ability of analyzing and solving problems, greatly promotes the students the spirit of exploration and innovation. At the same time it also increases the interest in the lab, stimulates the students' interest in learning, mobilizes the enthusiasm and initiative, is good for the cultivation of creative students' personality development, and overall quality enhancement, and to maximize the effect of experimental teaching.

\section{Encourage the Students to Participate in Social Practice}

In the teaching process, the so-called "social practice" usually refers to professional practice which relies on social resources in order to improve the teaching purpose, purposefully to production.

The method in the social practice is flexible, practical, effective, and is an important means to enable students to obtain the effect of integrating theory with practice. In fact, the case teaching, simulation training and experimental teaching belong to the practice category, but most of them are in the campus environment and lack of "real" state" of realistic society. The main ways to participate in social practice: one is for schools to the production sector counterparts, to establish the practice base fixed professional; the other one is to promote the students' spare time to contact personalized internship units. Let the students to practice basement and practice unit understanding the true post-press processing. It not only can further enhance the ability of the students application ability, to learn the basic knowledge of theory and raise the adaptability, but also can improve the students to accept new things students society.

\section{Conclusions}

This paper is some experience and harvest in the course construction and reform. The course construction and reform is an eternal theme, which need our further exploration and practice, to promote the better course construction effect and to greater enhance the teaching quality. To establish the correct positioning and suitable curriculum system and personnel training, focusing on application and employment, making course system and contents of characteristic, we have a lot of work to do. It needs to continuously and dynamically construction and teaching reform, especially in the cultivation of students' innovation ability and practice ability.

\section{References}

[1] Bo Gao, Wang Wei Min: Science and Technology Innovation Herald, No.1(2010), p.100. In Chinese.

[2] Bo Gao, Wang Yu: China Printing and Packaging Study, Vol.02, No.4 (2010), p.54. In Chinese.

[3] Ze-ying CHEN, Project Teaching Preliminarg Research Based on Mechanical Design, vol.119, pp.180-181, 2011. In Chinese.

[4] Ping Xi, Yang Yang and Chunjie Wang: Experimental Technology and Management, Vol.27, No.7 (2010), p.14. In Chinese. 